\title{
Clopidogrel versus Prasugrel in dual Platelet inhibition on elderly patients with acute coronary syndrome - the CLOPRA study
}

\author{
Authors: \\ Piper, Jörg, Prof. Dr. (corresponding author) \\ Senior Consultant \\ Department for Internal Medicine \\ and Cardiovascular Medicine \\ Clinic Meduna \\ Clara-Viebig road 4 \\ D-56864 Bad Bertrich \\ Germany \\ Email: webmaster@dr-piper.de,webmaster@prof-piper.de \\ Phone: +49-(0)2674-182-3184 \\ Fax: +49-(0)2674-182-3182 \\ Walscheid, Rüdiger, Dr. \\ Head of MVZ Koblenz \\ Center for Laboratory Diagnostics \\ Viktoria street 39 \\ D-56068 Koblenz \\ Germany \\ Email:walscheid@mac.com \\ Phone: +49-(0)261-3040513 \\ Tennant, Linda ( $\dagger$ ) \\ M.B., Ch. B. (Univ.Glasgow) \\ Department for Internal medicine \\ and Cardiovarcular Medicine \\ Clinic Meduna \\ Clara-Viebig road 5 \\ D-56864 Bad Bertrich \\ Germany \\ Email: scotlinda@freenet.de \\ Phone: +49-(0)2674-182-3184
}

This article is dedicated to the memory of LindaTennant

Conflicts of interest: none declared.

DOI: http://dx.dio.org/10.18103/mra.v0i4.343 


\begin{abstract}
Our study carried out in elderly and multimorbid patients with acute coronary syndrome initially treated with ASS (100 mg per day) plus Clopidogrel ( $75 \mathrm{mg}$ per day) was focused at Clopidogrel low- and non-responders. Moreover, we intended to clarify how far patients with reduced Clopidogrel response can profit by switching to Prasugrel.
\end{abstract}

In 178 patients (mean age: $74.1 \pm 0.6$ years) Thrombocyte Reactivity Indices (TRI) were measured by VASP-tests. Patients showing a limited Clopidogrel response (low- and nonresponders) were switched to Prasugrel $(60 \mathrm{mg}$ loading dose followed by 5 or $10 \mathrm{mg}$ maintenance dose per day; $10 \mathrm{mg}$ as standard dose, $5 \mathrm{mg}$ in patients aged 75 years or older or weighting $60 \mathrm{Kg}$ or less). Patients who were switched to Prasugrel were controlled by further VASP-tests. Additional evaluations were made for several subgroups of different age and gender. All patients were treated in a rehabilitation unit (Clinic "Meduna", Bad Bertrich, Germany), VASP-tests were carried out in a specialized laboratory (Center for Laboratory Diagnostics, Koblenz, Germany).

In elderly patients the fraction of Clopidogrel low- and non-responders tended to higher proportions than in younger patients (34.8 versus $46.8 \%$ ). In all cases with limited Clopidogrel response thrombocyte reactivity could be lowered by switching to Prasugrel. In patients of 75 years or older, or weighting less than $60 \mathrm{KG}$, a daily dose of $5 \mathrm{mg}$ Prasugrel led to the same sufficient reduction of thrombocyte reactivity as in the other patients given $10 \mathrm{mg}$ per day. After drug-switching circa $6 \%$ remained low- or non responders regardless of whether they were treated with 5 or $10 \mathrm{mg}$ Prasugrel. In patients successfully switched to Prasugrel we found the same reduction of thrombocyte reactivity as in Clopidogrel responders (mean TRI: 19\%); all of our patients treated as described were free from any bleeding complications.

All in all, Prasugrel seems to be more effective in lowering thrombocyte reactivity also in elderly patients, because the proportion of patients with limited response is much lower than in patients treated with Clopidogrel.

\title{
Keywords
}

Clopidogrel, Prasugrel, acute coronary syndrome, ACS, elderly patients, responders, non responders, VASP-test, thrombocyte reactivity index, TRI, drug interaction 


\section{Introduction}

According to generally accepted standards patients with a recent occurrence of acute coronary syndrome (ACS) should have a dual antiplatelet therapy (DAPT) based on ASS plus $\mathrm{P}_{2} \mathrm{Y}_{12}$ receptor antagonist continued for 12 months; following this, a single thrombocyte aggregation inhibitor preferably acetylsalicylic acid (ASS) should be maintained.

Limitations of a dual platelet inhibition with ASS plus Clopidogrel arise from a possible resistance to Clopidogrel, which may be found in 4 to over 30 percent (depending on the author) of all patients treated $(1,15,17,24,28)$. On average, about every third patient shows resistance to Clopidogrel, about every fifth patient to ASS (19). Resistance to ASS seems to have similar pejorative effects on the prognosis of subsequent cardiovascular incidents (29), as resistance to $\mathrm{P}_{2} \mathrm{Y}_{12}$ receptor antagonists (21). In particular, the risks of subsequent recurrence of ACS and stent-thrombosis are increased $(\mathbf{1 9}, \mathbf{1 4}, \mathbf{2 0})$.

Patients proved to be Clopidogrel-resistant can be treated with newer $\mathrm{P}_{2} \mathrm{Y}_{12}$-receptorantagonists. Prasugrel is the first representative of this new generation of drugs. It is activated via only one stage of metabolism (31), it reaches its level of efficiency faster and induces a stronger maximal platelet inhibition (31). Genetic polymorphs of the Cytochrome isoenzymes have less inhibitory effect on the activation of Prasugrel than in the case of Clopidogrel (30). Consequently, variations in efficiency from patient to patient are markedly less obvious than for Clopidogrel (9).

According to manufacturers' recommendations (published in Europe), elderly patients ( $\geq 75$ year old) and patients of low weight $(<60 \mathrm{~kg})$ should be given a half maintenance dose when treated with Prasugrel (5 mg instead of $10 \mathrm{mg}$ ). However, this reduction of dose is not generally accepted (and therefore not worldwide recommended up till now). As shown in the GENERATIONS trial, $5 \mathrm{mg}$ Prasugrel lead to adequate platelet inhibition in 155 elderly patients with stabile angina pectoris (12).

In our study, 178 elderly patients with ACS are evaluated with regard to their Clopidogrel and Prasugrel response. Based on VASP tests, the efficiency of platelet inhibition achieved with Clopidogrel was compared with that achievable by switching to Prasugrel (5 or $10 \mathrm{mg}$ ) in those patients showing a limited Clopidogrel response. It was further evaluated, which responder rates can be achieved when such patients affected with a limited Clopidogrel response are switched to Prasugrel. Lastly, we examined whether differences of age, gender or influences of co-medications or comorbidity can be proved to affect Clopidogrel resistance. The aggregation inhibitory effect achieved with Prasugrel or Clopidogrel was evaluated in all of our patients and in several patient subgroups; all parameters measured were submitted to comparative statistical analyses.

\section{Material and methods}

\subsection{Patient groups}

Inclusion criteria: acute ACS (Non ST Elevation Myocardial Infarction/NSTEMI or ST Elevation Myocardial Infarction/ STEMI) treated with ASS (100 mg per day) plus Clopidogrel (75 mg per day).

A total of 178 in-patients was recruited, who were treated in the clinic "Meduna", Bad Bertrich, Germany over a period of two years following a recent acute coronary syndrome (ACS, NSTEMI or 
STEMI). Each patient had been previously treated for a few days in an outside acutecare hospital; the acute coronary syndrome had occurred at an average of 7-10 days before admittance here.

Exclusion criteria: Clopidogrel monotherapy (where ASS was not tolerated), simultaneous treatment with Coumarins and other newer oral anticoagulants (tripletherapy), contra-indications for treatment with Prasugrel according to the generally accepted recommendations (pathologic bleeding, e.g. peptic ulcer, intracranial hemorrhage, prior transient ischemic attack (TIA) or stroke, hypersensitivity).

Each patient accepted for the study was being treated on admission to our clinic with a dual platelet inhibition based on ASS and Clopidogrel and had been provided with one or more coronary stents in the previous clinic (Bare Metal
Stents/BMS or Drug Eluting Stents/DES). The majority of the patients belonged to an advanced age group, which showed corresponding multimorbidity and complex accompanying medication. The average age of the total patient group was $74.1 \pm$ 0.6 years (median: 75 years). The average age of all men was $73.0 \pm 0.9$ years (median: 74 years), that of the women 75.5 \pm 0.8 (median: 74 years); the global age structure of the study group is shown in Fig. 1. The fractions of men and women were balanced in the total group and in all subgroups analyzed.

Consequent to the advanced age of most patients several additional diseases to be treated were present, requiring a variety of co-medications. The most relevant codiseases documented are presented in Tab. 1, the most relevant medications applied, in Tab. 2.

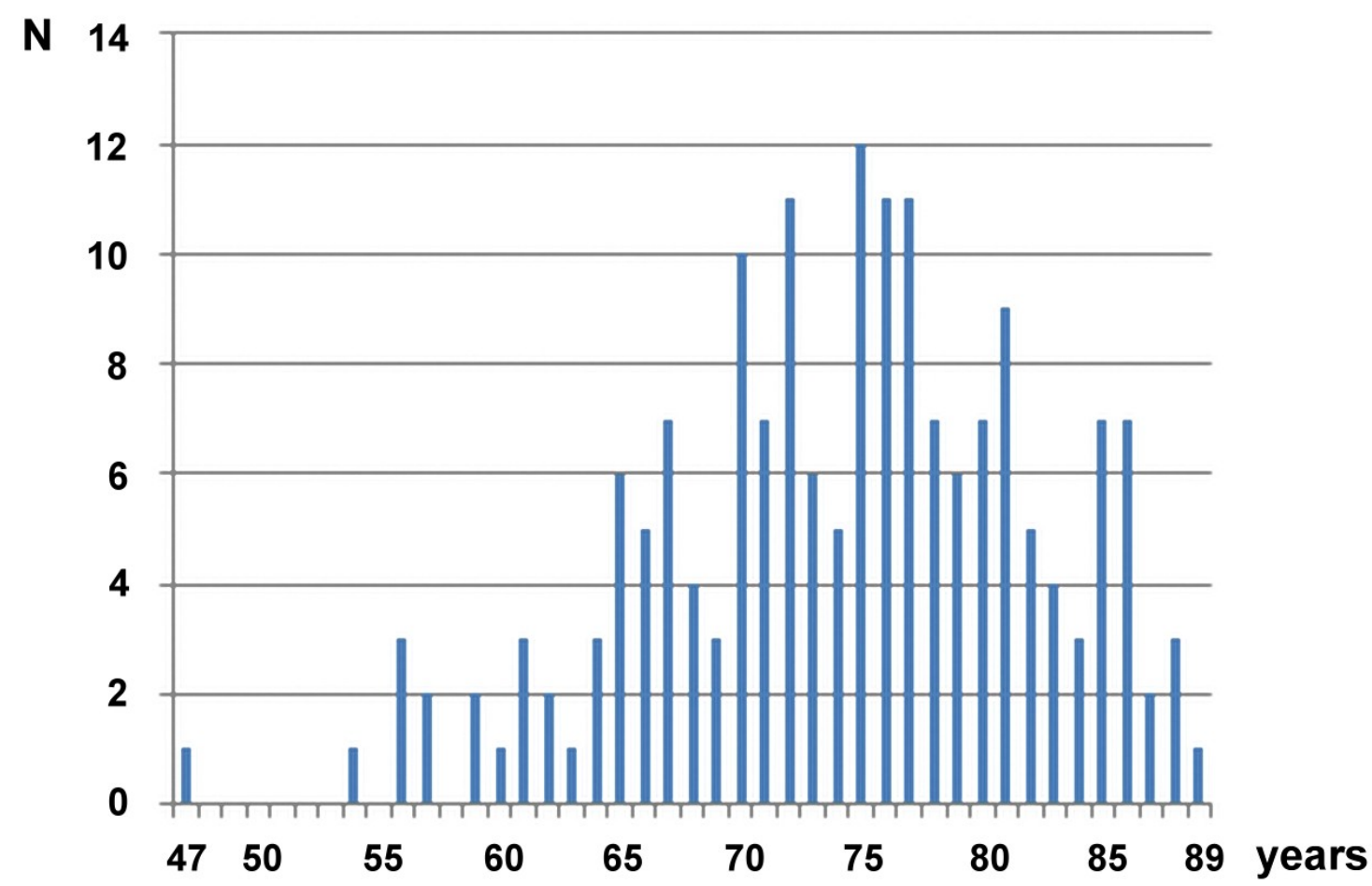

Fig. 1: Age distribution of all patients examined $(N=178)$ 
Tab. 1: Cardiac diagnoses and mostly found co-diagnoses (number of patients: $\geq 10$ ) in all patients examined $(\mathrm{N}=178)$

\begin{tabular}{|c|c|c|}
\hline Diagnosis & $\begin{array}{l}\text { Number of } \\
\text { patients }\end{array}$ & $\begin{array}{l}\text { Proportion } \\
\text { (percent) }\end{array}$ \\
\hline NSTEMI & 108 & $61 \%$ \\
\hline STEMI & 70 & $39 \%$ \\
\hline 3-vessel-CHD & 92 & $52 \%$ \\
\hline 2-vessel-CHD & 45 & $25 \%$ \\
\hline 1-vessel-CHD & 41 & $23 \%$ \\
\hline DES implantation & 95 & $53 \%$ \\
\hline BMS implantation & 83 & $47 \%$ \\
\hline hypertension & 140 & $79 \%$ \\
\hline dyslipidemia & 85 & $48 \%$ \\
\hline diabetes mellitus & 57 & $32 \%$ \\
\hline obesity & 39 & $22 \%$ \\
\hline renal insufficiency & 35 & $20 \%$ \\
\hline peripheral arterial occlusion disease & 31 & $17 \%$ \\
\hline neoplasm & 30 & $17 \%$ \\
\hline chronic obstructive pulmonary disease & 30 & $17 \%$ \\
\hline nicotine abusus & 21 & $12 \%$ \\
\hline depression & 20 & $11 \%$ \\
\hline hypothyreosis & 17 & $10 \%$ \\
\hline neurological disorders & 16 & $9 \%$ \\
\hline hyperuricemia & 14 & $8 \%$ \\
\hline aortic stenosis & 13 & $7 \%$ \\
\hline aortic insufficiency & 12 & $7 \%$ \\
\hline mitral insufficiency & 11 & $6 \%$ \\
\hline osteoporosis & 11 & $6 \%$ \\
\hline peripheral artery operation & 11 & $6 \%$ \\
\hline obstructive sleep apnea & 10 & $6 \%$ \\
\hline pacemaker & 10 & $6 \%$ \\
\hline
\end{tabular}


Tab. 2: Most relevant co-medications in Clopidogrel responders and low- or non-responder (number of patients: $\geq 5$ )

\begin{tabular}{|c|c|c|c|c|}
\hline Medications & $\begin{array}{l}\text { Number of } \\
\text { responders } \\
\text { ( } N=99 \text { ) }\end{array}$ & $\begin{array}{l}\text { Fraction of } \\
\text { responders } \\
\text { (percent) }\end{array}$ & $\begin{array}{l}\text { Number of } \\
\text { low- and } \\
\text { non resp. } \\
(\mathrm{N}=79)\end{array}$ & $\begin{array}{l}\text { Fraction of } \\
\text { low- and } \\
\text { non resp. } \\
\text { (percent) }\end{array}$ \\
\hline duale antiplatelet therapy & 99 & $100 \%$ & 79 & $100 \%$ \\
\hline lipid-lowering drugs & 86 & $86 \%$ & 73 & $94 \%$ \\
\hline beta blockers & 79 (!) & $79 \%(!)$ & $74(!)$ & $95 \%(!)$ \\
\hline diuretics & 66 & $66 \%$ & 56 & $72 \%$ \\
\hline proton pump inhibitors & 65 & $65 \%$ & 50 & $64 \%$ \\
\hline ACE inhibitors & 60 & $60 \%$ & 51 & $65 \%$ \\
\hline calcium channel blockers & 19 & $19 \%$ & 21 & $27 \%$ \\
\hline angiotensin II rezeptor blockers & 21 & $21 \%$ & 17 & $22 \%$ \\
\hline L-Thyroxine & 14 & $14 \%$ & 17 & $22 \%$ \\
\hline Insulin & 16 & $16 \%$ & 11 & $14 \%$ \\
\hline allopurinol & 15 & $15 \%$ & 10 & $13 \%$ \\
\hline bronchodilators & 15 & $15 \%$ & 8 & $10 \%$ \\
\hline antidepressive drugs & 10 & $10 \%$ & 10 & $13 \%$ \\
\hline dipeptidyl peptidase- 4 inhibitors & 12 & $12 \%$ & 8 & $10 \%$ \\
\hline metformin & 14 & $14 \%$ & 1 & $1 \%$ \\
\hline nitrates and nitrites & 9 & $9 \%$ & 4 & $5 \%$ \\
\hline morphine derivates & 9 & $9 \%$ & 3 & $4 \%$ \\
\hline non steroidal antirheumatic drugs & 12 & $12 \%$ & 0 & $0 \%$ \\
\hline benzodiazepines & 10 & $10 \%$ & 1 & $1 \%$ \\
\hline Amiodarone & 7 & $7 \%$ & 2 & $3 \%$ \\
\hline cortikosteroids & 6 & $6 \%$ & 2 & $3 \%$ \\
\hline moxonidin & 3 & $3 \%$ & 5 & $6 \%$ \\
\hline dipyramidole and other cor. dilatators & 7 & $7 \%$ & 0 & $0 \%$ \\
\hline Tamsulosin & 5 & $5 \%$ & 2 & $3 \%$ \\
\hline molsidomin & 5 & $5 \%$ & 0 & $0 \%$ \\
\hline ivabradin & 0 & $0 \%$ & 5 & $6 \%$ \\
\hline
\end{tabular}

\subsection{Laboratory diagnostics}

\subsubsection{Considerations on methods for measurement of platelet activity}

At present, several different procedures are available to carry out in-vitro measurements of pharmacologically induced inhibition of thrombocyte aggregation. These have been described in review articles $(\mathbf{1 8}$, 23). Breet et al. carried out comparative parallel measurements of thrombocyte aggregation using five different test procedures in 1069 coronary patients, who had elective stent implantations: conventional aggregometry, Verify Now, Plateletworks, IMPACT-R and PFA-100. The post-interventional follow-up lasted 12 months. Aggregometry, Verify Now and Plateletworks showed a good correlation with clinical end-points (death, acute coronary syndrome, stent thrombosis, ischemic cerebral insults and hemorrhagic complication), whereas IMPACT-R and PFA-100 showed no significant correlation (11). 
Paniccia et al. could show, in 1267 patients with acute coronary syndrome, that there are significant correlations and agreements between aggregometry, verify Now and VASP-test (25). Especially the VASP-test showed a good correlation to stentthromboses $(\mathbf{2 5}, \mathbf{1 6}, \mathbf{7})$. A strong agreement between aggregation measurements with Verify Now and VASP-test could also be shown by Bidget et al. (5). VASP-test and Verify Now also showed the best correlation with the plasma concentration of active Clopidogrel metabolites, so that these two tests were particularly recommended for monitoring Clopidogrelinduced platelet inhibition (10). The VASP test has a very high prognostic value for ischemic events in patients undergoing treatment with $\mathrm{P} 2 \mathrm{Y}_{12}$-receptor antagonists following PCI (26).

In contrast to Verify Now, no fresh blood is necessary for a VASP text. Instead, 10 $\mathrm{ml}$ of blood can be drawn into standard citrate tubes, as are also used for routine diagnostics in clotting mechanisms. The specimens drawn can be stored at room temperature and can be processed within a time window of 48 hours.

In consideration of all aspects mentioned, we decided to use VASP test for evaluation of Clopidogrel and Prasugrel response.

\subsubsection{Diagnostic workflow}

VASP tests were carried out by the Center for Laboratory Diagnostics, Koblenz, Germany, based on the method described by Schwarz (27). We used a standardized kit from the manufacturer Biocytex (PLT VASP/ P2 $\mathrm{Y}_{12}$-test); this assay can be used in citrated full blood. Platelets were marked with an antibody coupled with FITC; analyses were made with a flow cytometer Canto II from Becton \& Dickinson, Heidelberg, Germany. From each specimen five single analyses were carried out and averaged; variation coefficients were documented for quality control.

In a first phase of our experiment, the VASP-test used was calibrated for several months, using specimens from healthy subjects not under treatment with thrombocyte aggregation inhibitors. These measurements showed a good correlation to reference values given by the manufacturer; in healthy young people the standard value of Thrombocyte Reactivity Index (TRI) was $100 \%$; in healthy elderly persons it could physiologically decrease to circa $70 \%$.

In a second phase of test evaluation, repetitive TRI measurements were carried out in patients under Clopidogrel over a period of three following days.

The "cut-off" value of TRI, which indicates an insufficient aggregation inhibition, and thus a lack in response to the respective platelet inhibitor, was defined by Bonello as $\geq 50 \%(\mathbf{8}, \mathbf{6})$. Thus, an index of $\geq 50 \%$ shows by definition a non-responder.

Through our comparative measurements in identical patients we could, however, show that the VASP test is affected with a relevant variation of values measured -, in a range which is comparable with usual enzymatic tests in laboratory medicine. Thus, for instance, repeated measurements in the same person, beginning with a reactive index of $50 \%$, could "spontaneously" be reduced by 10 , corresponding to a value of $40 \%$. Consequently we determined that TRI between $40 \%$ and $50 \%$ corresponds to a diagnostic "shady or grey area" or to a questionable responder status, and so we defined patients with measurements in this area as "low responders". Sufficient 
platelet inhibition under Clopidogrel (status of a definite responder) we thus categorized as a TRI $\leq 40 \%$.

Following these evaluation phases we started with routine measurements in elderly ACS patients treated with $\mathrm{P}_{2} \mathrm{Y}_{12}$ inhibitors over a period of two following years.

All patients in the study group were tested for thrombocyte- reactivity within the frame work of the routine lab-work on the day of admission. For this purpose, $10 \mathrm{ml}$ of citrate blood (the usual "clotting monovette") were processed on the same day by a specialized laboratory. All specimens were taken in the morning between 7.00 and 9.00 , the laboratory analyses were performed in the afternoon of the same day.

\subsubsection{Clinical and therapeutic workflow}

All patients with a recent ACS, who fulfilled the inclusion criteria, underwent a VASP-test on the day of admission to determine their responder status under the initially existent dual platelet inhibition with ASS plus Clopidogrel. Those patients with a TRI under $40 \%$ were accepted as definite Clopidogrel responders, so that the dual platelet inhibition was carried on unchanged.

All non-responders (reactivity index $\geq$ $50 \%$ ) and also all low-responders (TRI $40 \%$ or more, but less than $50 \%$ ) were changed to Prasugrel directly on receiving the test results. This switching was carried out as an individual therapeutic decision of the physician responsible for the patients care, based on the patient's information and agreement. As only those patients were switched to Prasugrel who showed a limited Clopidogrel response and agreed with this modification of their medication based on an intensive personal conversation and individual medical advice, ethical approval was not necessary according to the given German law. On the first day, a loading dose of $60 \mathrm{mg}$ Prasugrel was given, from the second day on, the specific maintenance dose. Patients under 75 years weighting more than $60 \mathrm{~kg}$ were given a daily maintenance dose of 10 $\mathrm{mg}$, patients of 75 years or older, or weighting less than $60 \mathrm{~kg}$ were given a daily dose of $5 \mathrm{mg}$ Prasugrel.

8-10 days after change of therapy a VASPtest was carried out as a check on low- and non-responders switched to Prasugrel. In this way it could be determined how many Clopidogrel low- or non-responders converted to responders through change to Prasugrel. In the subgroup of patients on 5 mg Prasugrel it could also be tested how effective this daily-half dose was as a practical alternative with regard to responder status. Those few patients who did not show an appropriate reactivity index in the therapeutic spectrum under 5 mg Prasugrel were dismissed with a recommendation to increase the daily dose to $10 \mathrm{mg}$ and later carry out a further control of the reactivity index on an outpatient basis

The flow diagram in Fig. 2 gives an overview of the design and "work flow" of our study. 


\section{Initial thrombocyte-reactivity (VASP-test)}

$$
\begin{aligned}
\text { Index }<40 \% & \rightarrow \text { Clopidogrel continued } \\
\frac{\text { Index } \geq 40 \%}{\downarrow} \rightarrow & \text { Clopidogrel non-responder (TRI } \geq 50 \%) \\
& \text { Clopidogrel low-responder }(\mathrm{TRI}<50 \% \text { and } \geq 40 \%)
\end{aligned}
$$
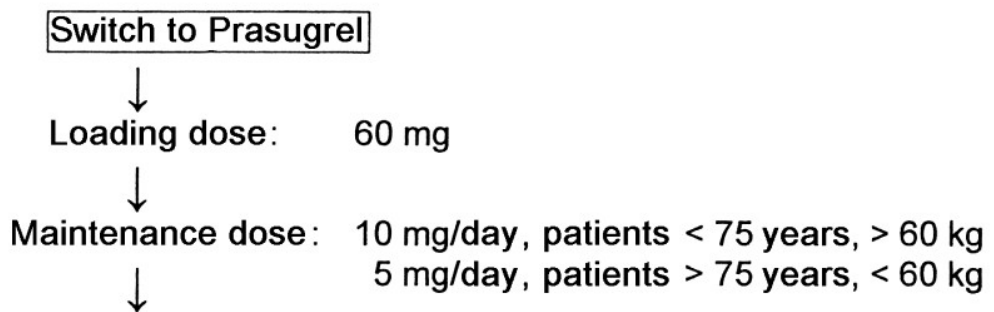

Thrombocyte-reactivity in patients switched to Prasugrel

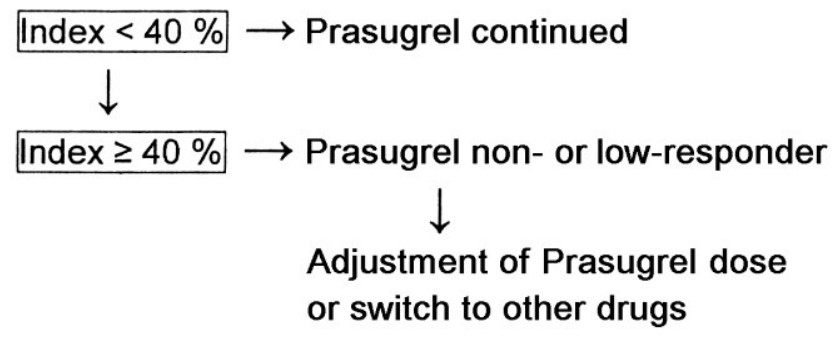

Fig. 2: "Work flow" of TRI measurements and drug switching

\subsubsection{Statistical tests}

Qualitative characteristics of the total group and of some sub-groups were tested for statistical significance using the Chi-Square-test. For quantitative statistic analyses (testing the significance of various quantitative deviations) IBM $^{\circledR}$ SPSS $^{\circledR}$ Statistics Version 22 (recent upgrade for 2013) for MAC was used. The normal scatter was tested by the Kolmogorov-Smirnov-test. Differences between groups were analyzed using the T-test and Mann-Whitney-U-test.

\section{Results}

\subsection{Basic results}

The fractions of low- and non responders in the total group and four patient subgroups ( 75 years and above, 70 years and above, 70 up till 75 years, and 69 years or younger) are shown in Fig. 3. It is clearly to see that the problem of Clopidogrel resistance remains highly relevant in patients of advanced age, independent of gender. 


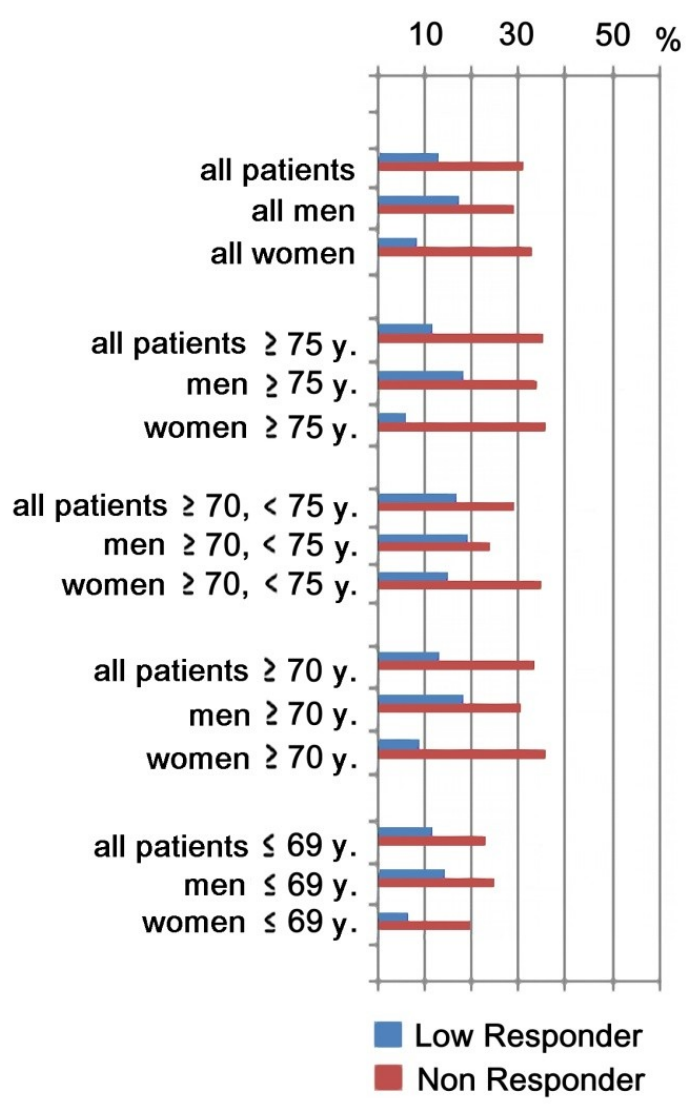

Fig. 3: Fractions of Clopidogrel low- and non-responders in several sub-groups of patients examined [\%]

Of the total of 79 patients who were detected as non responders $(\mathrm{N}=57)$ or low responders $(\mathrm{N}=22), 46$ patients $(58 \%$ of those affected) could be switched from Clopidogrel to Prasugrel during their stay in our clinic. In the sub-group of patients aged over $75(\mathrm{~N}=94)$ containing 33 nonresponders and 11 low-responders, 25 patients $(56 \%)$ could be switched to Prasugrel. The larger sub-group of patients aged 70 years and more contained 63 lowand non-responders (45 non-responders and 18 low-responders); of these, 36 patients $(57 \%)$ could be switched to Prasugrel.

The remaining low- and non-responders were not switched to Prasugrel, either because the patients themselves refused or they were dismissed from inpatient-care before completion. Nevertheless, all of these low- and non-responders who were not switched over by us were recommended to change to Prasugrel.

All in all, we did not see any complications associated with DAPT either in patients treated with Clopidogrel or in those patients who were switched to Prasugrel, in particular, we did not see any bleeding.

\subsection{Change in the responder status after switching from Clopidogrel to Prasugrel}

In the total of 46 patients who were switched from Clopidogrel to Prasugrel, a repeat check of the VASP-test was carried out 8-10 days after switching. From the measurements gained in this way, we could quantitatively derive all reductions of original TRI values achieved by switch to Prasugrel calculated in percent for all of these patients and subgroups mentioned above (see section 3.1). The results of these calculations are shown in Fig. 4. 


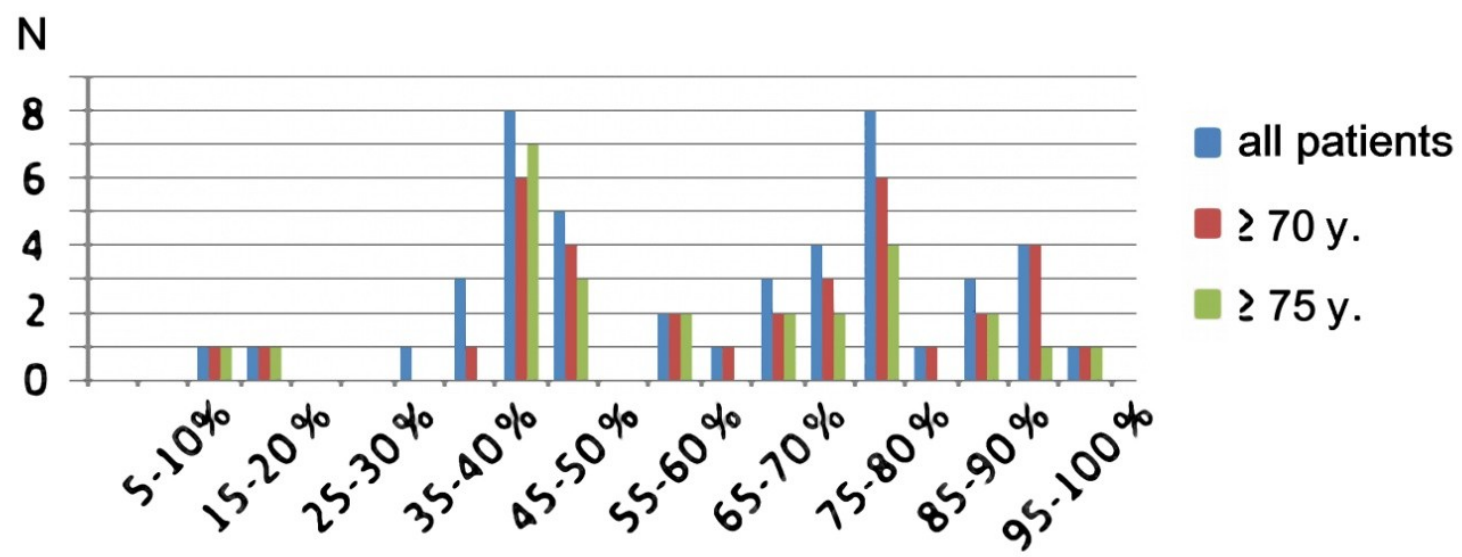

Fig. 4: Reductions of TRI achievable by drug switching from Clopidogrel to Prasugrel, evaluated in Clopidogrel low- and non-responders, calculated in percent and demonstrated for several categories of age range

In the total group the initial values of TRI determined in all low- and non-responders could be decreased by $57 \%$ on average (arithmetic mean) or by $63 \%$ (median). A similar reduction was also shown in the sub-group of patients of 70 years or above (reduction by 58 or $63 \%$, arithmetic mean and median). In the sub-group of patients aged 75 years or more, there resulted an average reduction of the originally measured reactivity indices by 53-54 \% (median or arithmetic average). On the whole, no patient was noted where the switch from Clopidogrel to Prasugrel had not caused a reduction in the reactivity indices originally measured. Thus, the entire low- and non-responders could reduce their initially measured values by switching to Prasugrel.

In spite of this favorable effect, a total of six patients was noted who could not be brought into a responder status, as defined, by changing to Prasugrel. These cases are sketched briefly in Tab. 3.

Tab. 3: Prasugrel low- and non-responders $(N=6)$

\begin{tabular}{llccc}
\hline Age (years) & Gender & TRI I (\%) & TRI II (\%) & $\begin{array}{c}\text { Dose of Prasugrel } \\
\text { (mg) }\end{array}$ \\
\hline 77 & & & & \\
76 & fem. & 60 & 56 & 5 \\
73 & fem. & 71 & 42 & 5 \\
67 & fem. & 80 & 56 & 5 \\
56 & male & 67 & 50 & 10 \\
56 & male & 75 & 50 & 10 \\
& male & 71 & 50 & 10 \\
\hline
\end{tabular}




\subsection{Quantitative statistical analyses of the Thrombocyte Reactivity Indices (TRI) measured}

An overview of all TRI measurements carried out is given in Fig. 5. Obviously, patients showing a limited Clopidogrel response could be successfully converted to adequate platelet inhibition by switching to Prasugrel $(\mathrm{p} \leq 0.0001)$. Significant ageand gender-dependent differences could not be proved.

For the subgroup of 46 Clopidogrel lowand non-responders, who could be switched to Prasugrel during the rehabilitation treatment, the relevant, originally measured TRI under Clopidogrel was $59.39 \pm 1.72 \%$, SD: $11.7 \%$, median: $58 \%$, range: $40-83 \%$. If the six patients previously mentioned, who did not achieve the so-defined responder status even after switching medication, were removed from the group, 40 definite Prasugrel responders remain. These showed under Prasugrel an average TRI of $20.6 \pm 1.50 \%$, SD: $9.5 \%$, median: $19 \%$, range: 7-36. This corresponds to the average TRI under Clopidogrel response $(19.08 \pm 1.16 \%)$.

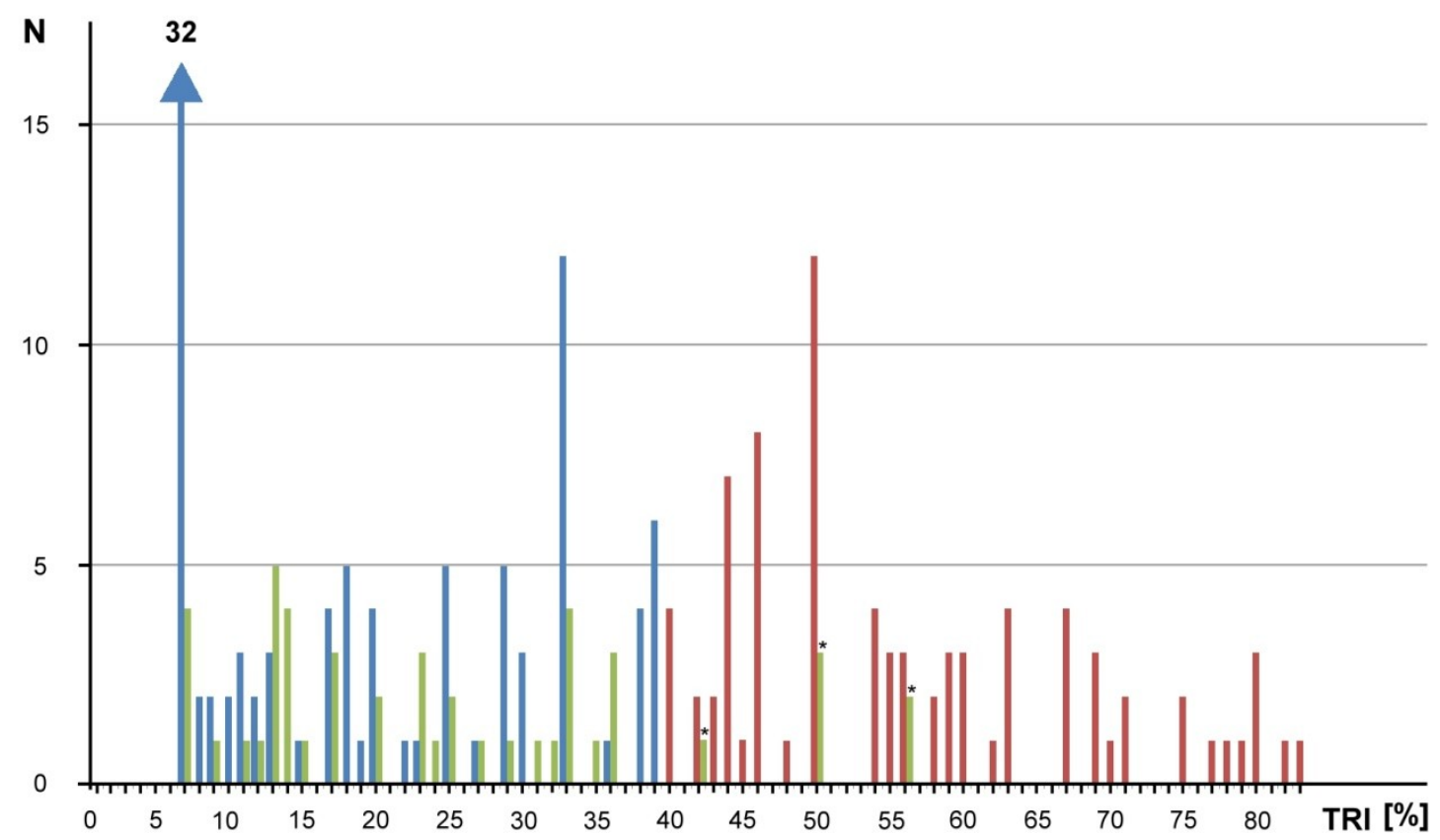

Fig. 5: Overview of all TRI values measured.

Blue: Clopidogrl responders ( $N=99$, mean TRI: $19.8 \pm 1.16 \%, S D: 11.5 \%$, median: $17 \%$, range: $7-39 \%)$. Red: Clopidogrel low- and non responders ( $N=79$, mean TRI: $56.52 \pm 1.36 \%$, SD: $12.1 \%$, median: $54 \%$, range: $40-83 \%)$. Green: Patients switched to Prasugrel $(N=46$, mean TRI: $24.52 \pm 2.01 \%$, SD: $13.6 \%$, median: $23 \%$, range: $7-56 \%)$. * Prasugrel low- and non-responders

In the 46 patients switched to Prasugrel an additional sub-group comparison with regard to age was carried out, in order to compare the therapeutic effects of a dose of $10 \mathrm{mg}$ Prasugrel (standard dose up till 74 years) as opposed to the reduced standard dose of $5 \mathrm{mg}$ at ages of 75 years and older.

In the Clopidogrel low- and nonresponders who were younger than 75 years $(\mathrm{N}=21)$, the average TRI original 
value under Clopidogrel was $58.33 \pm 2.51$ $\%$ (median: $58 \%$, range: $45-82 \%$ ). In the corresponding patients who were 75 years or older $(\mathrm{N}=25)$, there was an original value of $60.28 \pm 2.39 \%$ (median: $56 \%$, range: $40-83 \%$ ). These tiny differences in the measured values of both sub-groups were statistically not significant. After changing to Prasugrel (10 mg before 74 years, $5 \mathrm{mg}$ over 75 years) the TRI was highly significantly reduced in both age groups $(\mathrm{p} \leq 0.0001)$. In the under 75 -yearolds, there was a TRI value of $23.38 \pm 3.43$ $\%$ (median: $17 \%$, range: $7-56 \%$ ). In those patients aged at least 75 years, the corresponding TRI was $25.48 \pm 2.37 \%$ (median: $25 \%$, range: $7-56 \%$ ): The tiny numerical difference in TRI values of younger and older patients (23.38 versus $25.48 \%$ ) was statistically not significant. Thus, it may be deduced that at an age over 75 years, a daily dose of $5 \mathrm{mg}$ Prasugrel can achieve the same measurable effect as a $10 \mathrm{mg}$ dose in a younger patient.

\subsection{Evaluation of Co-morbidity}

Clopidogrel low- and non responders were not affected with simultaneous diseases in significantly higher proportions when compared with responders. Thus, none of the various co-diseases being immanent in the study group was associated with a higher proportion of non responders.

\section{Discussion}

According to our findings, up to $50 \%$ of elderly patients who survived ACS are affected with a limited Clopidogrel response whereas only $6 \%$ of patients switched to Prasugrel remain in a low- or non-responder status. The rate of Clopidogrel low- and non-responders does not decrease with increased age, but rather potentially increases. Men also seem to be more commonly affected, on the whole, by Clopidogrel resistance, than women. These trends, however, cannot be statistically confirmed as significant in the patient groups examined. Nevertheless, it can be derived from these findings that elderly patients suffering from ACS may have a significant benefit when treated with ASS plus new generation P2Y12 receptor antagonists instead of Clopidogrel so that they should be preferably treated by such a newer DAPT regime. In the future clinical outcome studies should be planned in order to confirm this plausible hypothesis.

As an essential result of the data collection presented, it can be noted that in all patients examined who had a decreased Clopidogrel response, a reduction in the thrombocyte reactivity index can be achieved by switching to Prasugrel - even in patients of advanced age beyond 70 or 75 years. This result corresponds with other findings evaluated on patients who were electively treated with coronary stents without running through a previous acute coronary syndrome (4). The vast majority of "switched" patients can also per definitionem be moved from the low- or non-responder status to a responder status; only in a few individual cases no sodefined response can be achieved by drug switching (3\% low- and $3 \%$ non responders). This finding corresponds with results of the ACAPULCO study (32); in this study, carried out with younger patients, up to $6 \%$ non-responders were found under Prasugrel and up to $34 \%$ under Clopidogrel.

It can also be deduced from our study that in the vast majority of aged patients with ACS, an effective response can be achieved using the reduced dose of $5 \mathrm{mg}$ Prasugrel daily. The TRI values of the elderly rehabilitation patients treated with $5 \mathrm{mg}$ correspond to those of the younger patients treated with $10 \mathrm{mg}$ Prasugrel. This finding confirms corresponding results evaluated in 155 patients with stable coronary artery disease (GENERATIONS 
trial, 12). Moreover, Clopidogrel low- and non-responders can achieve aggregation inhibition of comparable standard to Clopidogrel responders through switching to Prasugrel.

Clopidogrel-drug interactions have been described by several authors $(2,3,13,22)$. In our study group we compiled all comedications (see Table 2), but the design of our trial was not intended to establish such interaction. We recommend making further separate studies to evaluate drug interactions with sample specifically selected for that aim.

Although our patients were affected with several co-diseases, none of these diseases was associated with limited Clopidogrel response in a higher proportion when compared with responders. This finding can also be regarded as unexpected, too, because especially renal insufficiency and diabetes mellitus can modulate therapeutic effects of drugs and drug interactions in many cases.

\section{Acknowledgements}

The authors thank Mrs. Josefine Menzel, Hamburg, Germany for support in quantitative statistical analyses of all TRIvalues measured. 


\section{References}

(1) Aleil B, Ravanat C, Cazenave JP, Rochoux G, Heitz A, Gachet C. Flow cytometric analysis of intraplatelet VASP phosphorylation for the detection of clopidogrel resistance in patients with ischemic cardiovascular diseases. Thromb Haemost 2005; 3: 85-92

(2) Bassand JP. Drug interactions in the setting of acute coronary syndromes and dual anti-platelet therapy. EUR Heart J 2006; Supplement G: 35-37

(3) Bates ER, Lau WC, Angiolillo DJ.: Clopidogrel-drug interactions. J Am Coll Cardiol. 2011; 15; 57(11):1251-63

(4) Bernlochner I, Mayer K, Morath T, Orban $M$, Schulz S, Schomig A, Braun S, Kastrati. A, Sibbing D. Antiplatelet efficacy of prasugrel in patients with high onclopidogrel treatment platelet reactivity and a history of coronar stenting. Thromb. Haemost. 2013; 109 / 3: 361-567

(5) Bidet A, Jais C, Puymirat E, Coste P, Nurden A, Jakubowski J, Nurden P. Verify Now and VASP phosphorylation assays give similar results for patients receiving clopidogrel, but they do not always correlate with platelet aggregation. Platelets 2010; 21(2): 94-100

(6) Bonello L, Armero S, Ait Mokhtar O, Mancini J, Aldebert P, Saut N, Bonello N, Barragan $\mathrm{P}$, Arques $\mathrm{S}$, Giacomoni MP, Bonello-Burignat C, Bartholomei $\mathrm{MN}$, Dignat-George F, Camoin-Jau L, Paganelli F. Clopidogrel loading dose adjustment according to platelet reactivity monitoring in patients carrying the $2 \mathrm{C} 19 * 2$ loss of function polymorphism. J Am Coll Cardiol 2010 b; 56: 1630-1636
(7) Bonello L, Paganelli F, Arpin-Bornert M, Auquier P, Samprol J, Dignat-George F, Barragan P, Camoin-Jau L. Vasodilatatorstimulated phorphoprotein phosphorylation analysis prior to percutaneous coronary intervention for exclusion of postprocedural major adverse cardiovascular events. J. Thromb. Haemost. 2007; 5: $1630-1636$

(8) Bonello L, Tantry U., Marcucci R, Blindt $\mathrm{R}$, Angiolillo DJ, Becker R, Bhatt DL, Cattaneo M, Collet JP, Cuisset T, Gachet C, Montalescot G, Jennings IK, Keraiakes D, Sibbing $D$, Trenk $D$, Van Werkum JW, Paganelli F, Price MJ, Waksman R, Gurbel $P A$. Consensus and future directions on the definition of high on-treatment platelet reactivity to adenosine diphosphate. J Am Coll Cardiol 2010 a; 56(12): 919-933

(9) Brandt JT, Payne CD, Wiviott SD, Weerakkody G, Farid NA, Small DS, Jakubowski JA, Naganuma H, Winters KJ. A comparison of prasugrel and clopidogrel loading doses on platelet function: magnitude of platelet inhibition is related to active metabolite formation. Am Heart $J$ 2007; 153(1)/66: e9-16

(10) Bouman HJ, Parlak JW, van Werkum $\mathrm{W}$, Breet $\mathrm{NJ}$, ten Cate $\mathrm{H}$, Hackeng $\mathrm{CM}$, Ten Berg, JM, Taubert D. Which platelet function test is suitable to monitor clopidogrel responsiveness? A pharmacokinetic analysis on the active metabolite of clopidogrel. J. Thromb. Haemost 2010; 8: 482-488 
(11) Breet NJ, van Werkum JW, Bouman HJ, Kkelder JC, Ruven HJT, Bal ET, DEneer VH, Harmsze AM, van der Heyden JAS, Rensing BJWM, Suttorp MJ, Hackeng, CM., ten Berg JM. Comparison of platelet function tests in predicting clinical outcome in patients undergoing coronary stent implantation. JAMA 2010; 303(8): 754-762

(12) Erlinge D, Gurbel PA, James S, Lindahl $T L$, Svensson $P$, Ten Berg JM, Foley DP, Wagner $\mathrm{H}$, Brown PB, Luo J, Zhou Ch, Moser BA, Jakubowski JA, Small D, Winters $\mathrm{K}$, Angiolillo DJ. Prasugrel $5 \mathrm{mg}$ in the very elderly attenuates platelet inhibition but maintains noninferiority to prasugrel 10 $\mathrm{mg}$ in nonelderly patients: the GENERATIONS trial, a pharmacodynamic and pharmacokinetic study in stable coronary artery disease patients. J Am Coll Cardiol 2013; 62 (7): 577-583

(13) Gaglia MA Jr, Waksman R.: Proton pump inhibitors and clopidogrel. Cardiovasc The. 2010; 28(3): 169-76

(14) Geisler T, Langer H, Wydymus $M$, Zürn Ch, Göhring K, May A, Gawaz M. Low response to Clopidogrel is Associated with Cardiovascular Outcome after Coronary Stent Implantation. Eur Heart J 2006; 27(20): 2420-2425

(15) Gurbel PA, Bliden KP, Hiatt BL, O'Connor CM. Clopidogrel for coronary stenting: response variability, drug resistance, and the effect of pretreatment platelet reactivity. Circulation 2003; 107: 2908-2913

(16) Gurbel PA, Bliden KP, Samara W, Yoho JA, Hayes K, Fissha MZR, Tantry US. Clopidogrel effect on platelet reactivity in patients with stent thrombosis: results of the CREST Study. J. Am. Coll Cardiol 2005; 46: $1827-1832$
(17) Gurbel PA, Cummings CC, Bell CR, Alford AB, Meister AF, Serebruany VL. Onset and extent of platelet inhibition by clopidogrel loading in patients undergoing elective coronary stenting: the Plavix Reduction Of New Thrombus Occurrence (PRONTO) trial. Am Heart J 2003; 145(2): 239-247

(18) Harrison P, Frelinger AL, Furmann MI, Michelson AD. Measuring antiplatelet drug effects in the laboratory. Thrombosis Research 2007; 120: 323-336

(19) Herrath D, Ludwig WD, Thimme W. Dual anti platelet therapy - time for drug monitoring? Arzneimittelbrief (AMB) 2011; 45: 33 (in German)

(20) Matetzky S, Shenkman B, Guetta V, Shechter $M$, Bienart $R$, Goldenberg I, Novikov I, Pres H, Savion N, Varon D, Hod $\mathrm{H}$. Clopidogrel resistance is associated with increased risk of recurrent atherothrombotic events in patients with acute myocardial infarction. Circulation 2004; 109(25): 3171-3175

(21) Mega JL ${ }^{1}$, Close SL, Wiviott SD, Shen L, Hockett RD, Brandt JT, Walker JR, Antman EM, Macias W, Braunwald E, Sabatine MS. TRITON-TIMI 38 (TRial to assess Improvement in Therapeutic Outcomes by optimizing platelet Inhibition with prasugrel 38 - Thrombolysis In Myocardial Infarction 38). N Engl J Med 2009; 360: 354.

(22) Lau WC, Waskell LA, Watkins PB, Neer CJ, Horowitz K, Hopp AS, Tait AR, Carville DG, Guyer KE, Bates ER. Atorvastatin reduces the ability of clopidogrel to inhibit platelet aggregation: a new drug-drug interaction. Circulation 2003;107: 32-37

(23) Michelson AD. Methods for the measurement of platelet function. Am J Cardiol 2009; 103 (suppl.): 20A-26A 
(24) Mobley JE, Bresee SJ, Wortham DC, Craft RM, Snider CC, Carroll RC. Frequency of nonresponse antiplatelet activity of clopidogrel during pretreatment for cardiac catheterization. Am J Cardiol. 2004; 93(4): 456-458

(25) Paniccia R, Antonucci E, Gori AM, Marcucci R, Giglioli C, Antonucci D, Gensini GF, Abbate R, Prisco D. Different methodologies for evaluating the effect of clopidogrel on platelet function in highrisk coronary artery disease patients. J Thromb Hemost 2007; 5: 1839-1847

(26) Schrör K, Kirch W. New anti platelet drugs in clinic and practice. Schattauer, 2013, ISBN: 978-3-7845-2926-I, pp. 81-85 (in German)

(27) Schwarz UR, Geiger J, Walter U, Eigenthaler M. Flow cytometry analysis of intracellular VASP phosphorylation for the assessment of activating and inhibitory signal transduction pathways in human platelets-definition and detection of ticlopidine/clopidogrel effects. Thromb Haemost 1999; 82: 1145-1152

(28) Serebruany VL, Steinhubl SR, Berger PB, Malinin Al, Bhatt DL, Topol EJ. Variability in platelet responsiveness to clodidogrel among 544 individuals. J Am Coll Cardiol 2005: 45(2): 246-51
(29) Snoep JD, Hovens MM, Eikenboom JC, van der Bom JG, Huisman MV. Association of laboratory-defined aspirin resistance with a higher risk of recurrent cardiovascular events: a systematic review and meta-analysis. Arch Intern Med. 2007;167(15): 1593-1599

(30) Varenhorst $C h$, James $S$, Erlinge $D$, Brandt JT, O'Braun O, Man M, Siegbahn A, Walker J, Wallentin L, Winters KJ, Close, SL. Genetic variation of CYP2C19 affects both pharmacokinetic and pharmacodynamic responses to clopi-dogrel but not prasugrel in ASS-treated patients with coronary artery disease. Eur Heart J 2009; 30(14):1744-1752

(31) Wiviott SD, Antmann EM, Braunwald E. Prasugrel. Circulation 2010; 122: 394403

(32) Wiviott SD, Braunwald E, McCabe $\mathrm{CH}$, Montelescort G, Ruzyllo W, Gottlieb S, Neumabnn FJ, rdissino D, De Servi $S$, Murphy SA, Riesmeyer J, Weerakody G, Gibson CM, Antmann EM. Prasugrel versus clopidogrel in patients with acute coronary syndromes. N Engl J Med 2007; 357: 2001-2015 